\title{
Mechanisms of Electrical Polarization of Disordered Systems Based on Al-Substituted LiFe-Oxospinel
}

\author{
${ }^{1}$ Vasyl Stefanyk Precarpathian National University, Ivano-Frankivsk, Ukraine, ivan.hasiuk@pnu.edu.ua \\ ${ }^{2}$ Ivano-Frankivsk National Technical University of Oil and Gas, Ivano-Frankivsk, Ukraine,
}

\begin{abstract}
The temperature-frequency dependences of the dielectric permittivity and conductivity of $\mathrm{Li}_{2} \mathrm{O}-\mathrm{Fe}_{2} \mathrm{O}_{3}-\mathrm{Al}_{2} \mathrm{O}_{3}$ ceramics in the temperature range of $298-648 \mathrm{~K}$ were obtained by impedance spectroscopy. Their analysis indicates the presence of a fractal-like structure in the studied samples, the effect of which is manifested at low temperatures. To study the phenomenon of electric polarization associated with this structure, we used the generalized law of Jonscher. A significant dependence of the dispersion of dielectric and conductive properties of these spinel ceramics on the temperature and aluminum content in them was revealed.

Key words: impedance spectroscopy, spinel, fractal-like structure, frequency dispersion of dielectric constant, dielectric susceptibility, dielectric loss angle tangent, conductivity hopping mechanism.
\end{abstract}

Received 6 May 2021; Accepted 14 June 2021.

\section{Introduction}

Complex lithium-containing oxide systems with a spinel structure have become interesting in recent years as promising materials for building on the basis of matrix systems of cathodes of lithium current sources, due to the presence of free crystallographic positions in their structure for efficient lithium intercalation. In [1], the prospect of replacing the traditional lithium-manganese spinel in lithium-ion batteries with a more stable lithiumiron oxospinel, more widely studied as a magnetic material, was shown. However, when using stoichiometric lithium ferrite as the cathode of lithium current source, a significant disadvantage is its low electronic conductivity under conditions of high values of intercalation characteristics. Therefore, studies of the effect of modification of the electrophysical characteristics of lithium-iron spinel by isovalent substitution, including iron ions - aluminum ions [2] have become relevant.

In $[3,4,5]$ was studied the morphology, phase content, crystal structure of the spinel phase of synthesized Al-substituted lithium-iron spinels with the general formula (1-y) $\mathrm{LiFe}_{5} \mathrm{O}_{8}+(\mathrm{y}) \mathrm{LiAl}_{5} \mathrm{O}_{8}$ depending on the composition and mode of heat treatment on the final stage of synthesis and their electrophysical characteristics. It is shown that substances with such a ratio of elements of the initial charge violate single-phase, and the distributed system is optimally suitable as a cathode material because it contains local areas for lithium intercalation, separated by formations with high electronic conductivity, which serve to transport electrons to the electrochemical reaction site. The study of the temperature dependences of the conductivity of the synthesized material [6] showed that the electronic component of the conductivity of these disordered systems can be realized by two mechanisms: hopping and activation. In [7], the temperature-frequency dependences of $\mathrm{Li}^{+}$-ionic conductivity at different values of aluminum content were interpreted on the basis of a generalized phenomenological model of charge transfer in superionics [8], the values of the concentrations of $\mathrm{Li}^{+}$-ions of conductivity, their macroscopic and microscopic mobilities in the whole investigated temperature range at different values of the aluminum content in the synthesized samples were obtained.

In the presented work on the basis of the analysis of behavior of frequency dispersion of dielectric characteristics using the generalized theory of Jonscher [9] the attempt to explain mechanisms of formation of 
polarization effects of the disordered system on the basis of $\mathrm{Al}$-substituted $\mathrm{LiFe}$-oxospinel is made.

\section{Research methods}

A series of samples with the expected composition of $(1-y) \mathrm{LiFe}_{5} \mathrm{O}_{8}+(y) \mathrm{LiAl}_{5} \mathrm{O}_{8}$ at a synthesis temperature of $1273 \mathrm{~K}$ was obtained by the ceramic method, which corresponds to the formula of stoichiometric lithiumaluminum-iron spinel [5]. Heat treatment at the final stage of the synthesis was performed with an average cooling rate $\mathrm{V}_{\mathrm{T}} \approx 0.03 \mathrm{~K} / \mathrm{s}$ (samples cooled together with the oven).

Conductive and dielectric properties of the synthesized compounds were calculated on the basis of experimental impedance spectrum obtained on an Autolab PGSTAT 12/FRA-2 spectrometer in the frequency range $0.01 \mathrm{~Hz}-100 \mathrm{kHz}$ and temperatures $298-648 \mathrm{~K}$. Temperature recordings were performed with isothermal exposure every $25 \mathrm{~K}$ [6].

\section{The results of the experiment and their discussion}

Temperature-frequency dependences of the electrical impedance of the studied samples are presented using experimental Nyquist diagrams (parametric frequency dependences of the real and imaginary part of the complex resistance $\left.\rho^{\prime}\left(\rho^{\prime \prime}\right)\right)$. Fig. 1 presents Nyquist diagrams for a sample of the initial composition $\mathrm{Li}_{0,5} \mathrm{Fe}_{2,5-y} \mathrm{Al}_{y} \mathrm{O}_{4}(\mathrm{y}=$ $0,6)$. The choice of the system with $y=0,6$ is motivated by the best suitability of intercalation-transport parameters of this composition for practical use as a cathode of lithium current sources [10].

The temperature dependence of the static conductivity $\sigma_{0}(T)$ was calculated from the dependences $\sigma^{\prime}(\omega)$ and $\sigma^{\prime \prime}(\omega)$ according to the models described in [10]. Its analysis showed that in the temperature range above 450 $\mathrm{K}$ in the synthesized ceramics $\mathrm{Li}_{2} \mathrm{O}-\mathrm{Al}_{2} \mathrm{O}_{3}-\mathrm{Fe}_{2} \mathrm{O}_{3}$ the dominant is ionic $\mathrm{Li}^{+}$- conductivity, the activation energy of which is in the range of $0.9-1.4 \mathrm{eV}$ [7].

In the range of temperatures below $450 \mathrm{~K}$, electronic conductivity becomes predominant, which can be realized by two mechanisms: hopping and activation [6]. Activation conductivity is carried out by drift in the electric field of free charge carriers generated in the conduction band from the valence band or from the donor levels. The hopping mechanism of electrical conductivity in these ceramics is mainly realized by the hop of an electron between ions of the same element (in this case it is ions $\mathrm{Fe}^{2+}$ and $\mathrm{Fe}^{3+}$ ), which can be in more than one valence state, randomly distributed in crystallographically equivalent octahedral lattice positions [11]. In the temperature range $295-350 \mathrm{~K}$, the hopping mechanism dominates, the activation energy of which is in the range of $0.10-0.14 \mathrm{eV}$, and in the temperature range $350-450 \mathrm{~K}$ - activation, with the activation energy $\Delta \mathrm{E} \sim$ $0.35 \mathrm{eV}$ [6].

The frequency dispersion of the dielectric loss tangent inhomogeneous substances, regardless of their specific

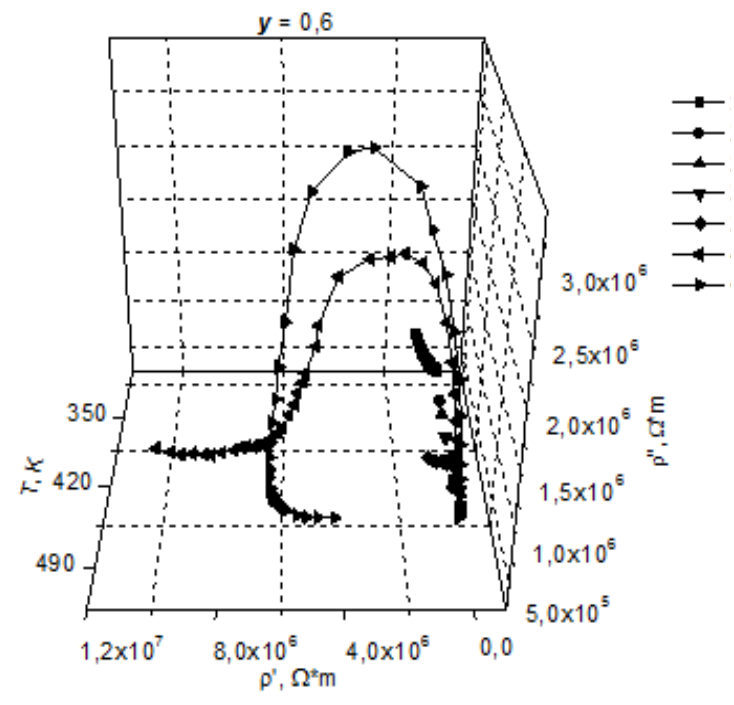

Fig. 1. Nyquist diagrams for specific values of the complex impedance $\rho^{\prime \prime}\left(\rho^{\prime}\right)$ at different temperatures for the studied samples with $\mathrm{y}=0.6$.

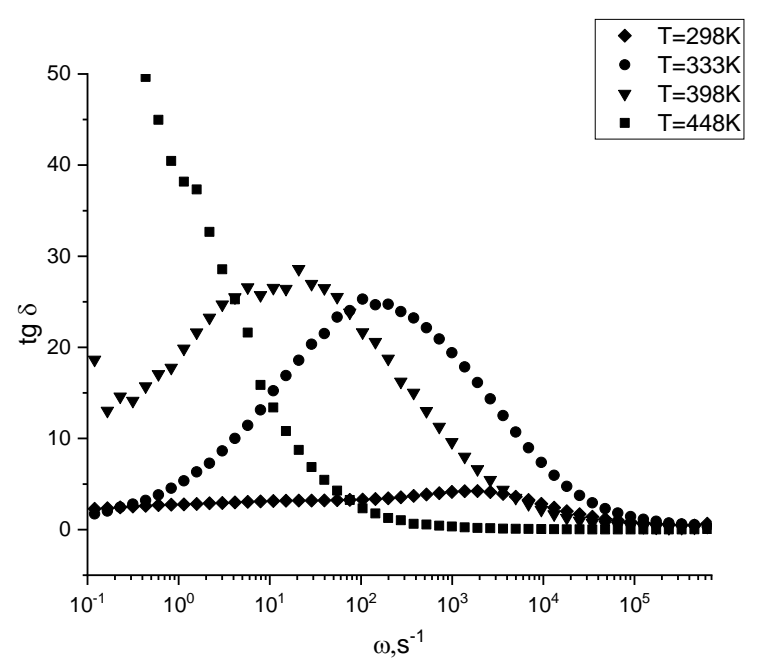

Fig. 2. Experimental dependences of the dielectric loss angle tangent on frequency for several temperature values in samples with $\mathrm{y}=0.6$.

$\operatorname{tg} \delta$ in the synthesized samples for the range of investigated temperatures is shown in Fig. 2. In [9] this behavior of dispersion curves of dielectric losses with pronounced maximum is associated with the manifestation of the fractal-like structure of the material.

As can be seen from the figure, with increasing temperature, the local maximum of dependence, which characterizes the resonant frequency of dielectric losses, shifts to the low frequency range and when the measurement temperature reaches $448 \mathrm{~K}$, its position is outside the investigated frequency range. The value of the maximum increases.

According to the generalized law of Jonscher [9], which satisfactorily describes the contribution of different mechanisms to the complex conductivity as a function of frequency for a wide class of different

structure, except for ordinary current due to free carriers 
$\vec{J}_{0}=\sigma_{0} \vec{E}$ and polarization current $\vec{J}_{\mathrm{p}}=\frac{\partial \vec{P}}{\partial t}$ caused by the occurrence of electric polarization dipoles, the current associated with a multilevel dispersed structure similar to a fractal structure, $\vec{J}_{\text {frac }}=\sigma_{\text {frac }}(\omega) \vec{E}$ and caused by local polarization with the resulting field of microstructural formations of the material, i.e. the total current is equal to:

$$
\vec{J}=\vec{J}_{0}+\vec{J}_{\mathrm{p}}+\vec{J}_{\text {frac }}=\sigma(\omega) \vec{E}
$$

where generalized conductivity normalized by constant $\frac{\varepsilon_{0}}{4 \pi}$

$$
\begin{aligned}
& \left(\varepsilon_{0}=8,85 \cdot 10^{-12} \frac{F}{m}\right) \\
& \sigma(\omega)=-i \omega\left(\varepsilon(\omega)-\varepsilon_{\infty}\right)
\end{aligned}
$$

is expressed through a complex dielectric constant, which takes the form of:

$$
\varepsilon(\omega)=\varepsilon_{\infty}+\frac{\sigma_{0}}{i \omega}+\frac{\chi \tau^{-v}}{i \omega+(i \omega)^{1-v} \tau^{-v}}+R(i \omega) .
$$

The penultimate term of this expression reflects the contribution to the dielectric permittivity of the fractal-like structure, and the last one - the contribution of relaxation processes, which in the case of migratory polarization is expressed by the Cole-Cole formula:

$$
R(i \omega)=\frac{\varepsilon_{0}-\varepsilon_{\infty}}{1+(i \omega \tau)^{v}} .
$$

In formula (3), the value $\chi$ determines the dielectric susceptibility of the fractal-like structure.

By simple algebraic transformations from the formula (3) we can find expressions for calculating the real and imaginary part of the complex dielectric permittivity:

$$
\begin{aligned}
& \varepsilon^{\prime}(\omega)=\operatorname{Re}[\varepsilon(\omega)]=\varepsilon_{\infty}+\frac{\chi \omega^{-v} \tau^{-2 v} \sin \sin \left(\frac{v \pi}{2}\right)}{\omega\left[1+2 \cos \cos \left(\frac{v \pi}{2}\right)(\omega \tau)^{-v}+(\omega \tau)^{-2 v}\right]}+\frac{\left(\varepsilon_{0}-\varepsilon_{\infty}\right)\left[1+\cos \cos \left(\frac{v \pi}{2}\right)(\omega \tau)^{v}\right]}{1+2 \cos \cos \left(\frac{v \pi}{2}\right)(\omega \tau)^{v}+(\omega \tau)^{2 v}} \\
& \varepsilon^{\prime \prime}(\omega)=\operatorname{Im}[\varepsilon(\omega)]=\frac{\sigma_{0}}{\omega}+\frac{\chi \tau^{-v}\left[1+\cos \cos \left(\frac{v \pi}{2}\right)(\omega \tau)^{-v}\right]}{\omega\left[1+2 \cos \cos \left(\frac{v \pi}{2}\right)(\omega \tau)^{-v}+(\omega \tau)^{-2 v}\right]}+\frac{\left(\varepsilon_{0}-\varepsilon_{\infty}\right)\left[1+(\omega \tau)^{v}\right]}{1+2 \cos \cos \left(\frac{v \pi}{2}\right)(\omega \tau)^{v}+(\omega \tau)^{2 v}}
\end{aligned}
$$

and also the tangent of the angle $\delta$ of dielectric loss:

$$
\tan \delta(\omega)=\frac{\varepsilon^{\prime \prime}(\omega)}{\varepsilon^{\prime}(\omega)}
$$

In Fig. 3-5 there are shown the experimental frequency dependences of the tangent of the dielectric loss angle, the real and imaginary part of the complex dielectric constant together with their approximating theoretical curves according to formulas (5) - (7) of the synthesized samples with $\mathrm{y}=0.6$ for three temperature values. The temperature values chosen by us to show the graphs in the figures correspond to the initial (low-frequency) phase of manifestation $(T=423 \mathrm{~K})$, the maximum value of the dielectric susceptibility $\chi$ of fractal-like structure $(\mathrm{T}=348 \mathrm{~K})$ and the lowest temperature of the studied temperature range $(\mathrm{T}=298 \mathrm{~K})$. The frequency experimental dependences at these temperatures correspond to the following values of the parameters of the approximating curves:

1) for $\mathrm{T}=423 \mathrm{~K}-\varepsilon_{\infty}=60 ; \varepsilon_{0}=3 \cdot 10^{4}$;

$\sigma_{0}=1,1 \cdot 10^{4} s^{-1} ; v=0,76 ; \tau=51 s ; \chi=2,3 \cdot 10^{3}$;

2) for $\mathrm{T}=348 \mathrm{~K}-\varepsilon_{\infty}=80 ; \varepsilon_{0}=10^{6}$; $\sigma_{0}=10^{6} s^{-1} ; v=0,79 ; \tau=1,76 s ; \chi=3,2 \cdot 10^{7}$;

3) for $\mathrm{T}=298 \mathrm{~K}-\varepsilon_{\infty}=15 ; \varepsilon_{0}=15$; $\sigma_{0}=5,6 \cdot 10^{4} s^{-1} ; v=0,3 ; \tau=10^{-3} s ; \chi=3,2 \cdot 10^{5}$.

Deviations observed in fig. 5 in the region of high frequencies of theoretical dependences of $\varepsilon^{\prime \prime}(\omega)$ on experimental ones, is not explained within the limits of the offered model as it does not consider contribution to the general conductivity of an ionic component.

The parameter $\tau$ has the meaning of the polarization relaxation time. At the temperature $\mathrm{T}=423 \mathrm{~K}$, at which the fractal-like structure begins to appear morphologically, it has the maximum and rather large value $(\tau \sim 10 \mathrm{~s})$, which sharply decreases to $\left(\tau \sim 10^{-3} s\right)$ with decreasing temperature. In our opinion, there is a close correlation between the size of fractal formations and the relaxation time, as well as the magnitude and position of the maximum of tangent of the dielectric loss angle in the studied frequency range. With increasing temperature, the morphological transformation of the test substance and the manifestation of certain fractal levels is carried out through the distribution of the formed

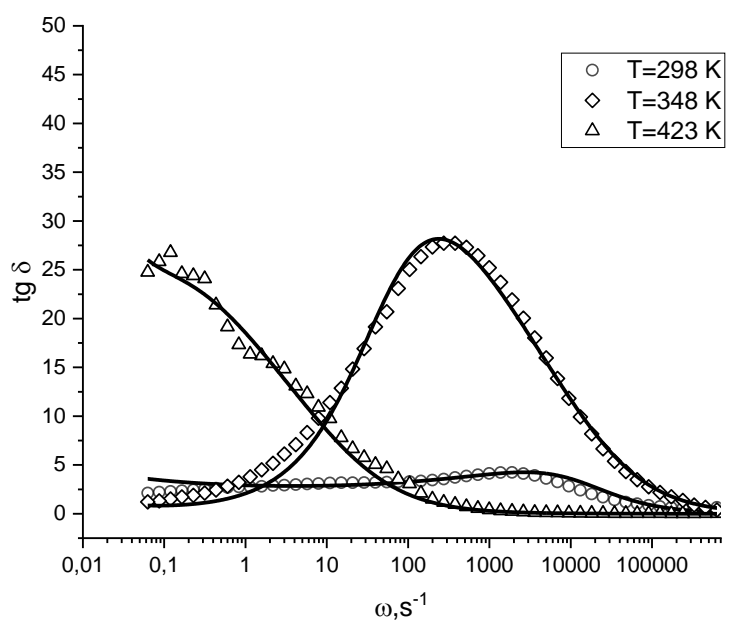

Fig. 3. Approximation of experimental dependences of the tangent of the dielectric loss angle on the frequency for several temperatures by theoretical curves obtained on the basis of (5) - (7), in samples with $y=0.6$. 


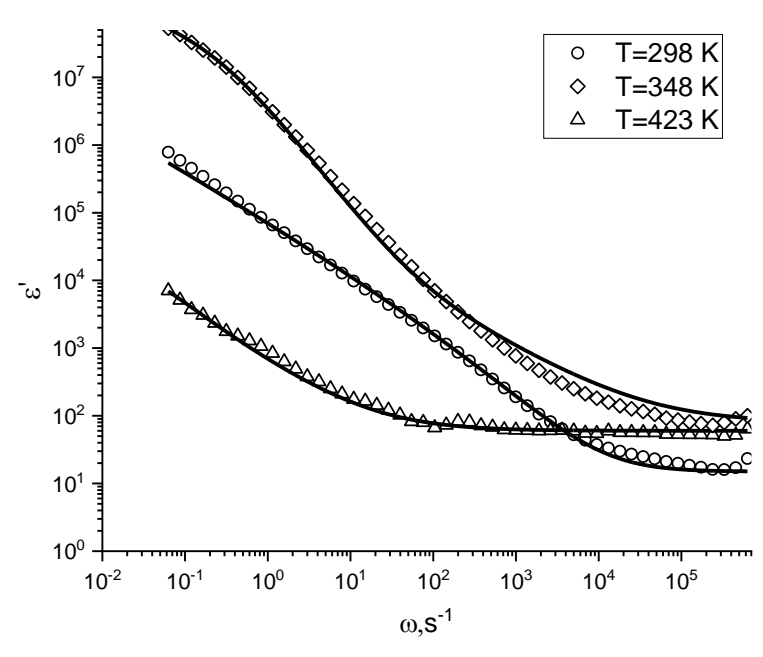

Fig. 4. Approximation of the experimental dependences of the real part of the complex dielectric permittivity on the frequency for several temperatures by theoretical curves obtained on the basis of (5) in samples with $\mathrm{y}=0.6$.

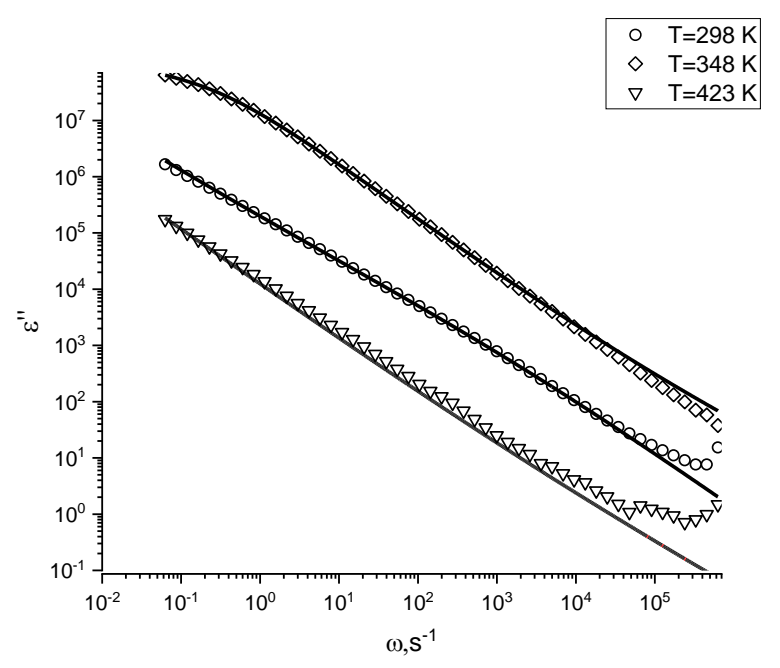

Fig. 5. Approximation of the experimental dependences of the imaginary part of the complex dielectric permittivity on the frequency for several temperatures by theoretical curves obtained on the basis of (6) in samples with $y=0.6$.

crystal grains by size and shape, inclusions of different phases and unequal coefficient of thermal expansion of crystal grains of different phases and intergranular boundaries.

The change in the value of the exponent of frequency in the Jonscher equation from $v=0,79$ for $\mathrm{T}=348 \mathrm{~K}$ to $v=0,3$ for $\mathrm{T}=298 \mathrm{~K}$ may indicate a replacement of the activation mechanism of electronic conductivity with the hopping one as being predominant. An additional evidence of this may be the fact that the coincidence of the approximating curve with the experimental dependence at room temperature occurs under the condition $\varepsilon_{0} \cong \varepsilon_{\infty}$, i. e. in the absence (or presence of insignificant) energy dissipation.

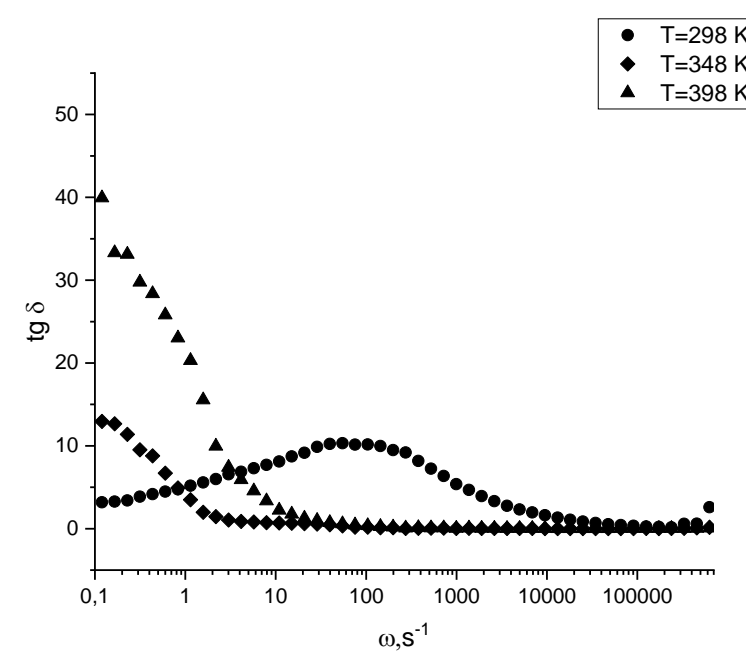

Fig. 6. Experimental dependences of the dielectric loss angle tangent on the frequency for several temperature values in samples with $\mathrm{y}=0.8$.

As the comparative analysis shows, the formation of fractal structure is significantly influenced by the aluminum content in the studied samples. Fig. 6 shows the experimental frequency dependences of the tangent of the dielectric loss angle of the synthesized samples $(y=0.8)$ for three temperature values. From the comparison of Fig. 6 with Fig. 2 it can be concluded that an increase in the aluminum content in the samples leads to a decrease in the temperature at which the fractal conductivity component begins to appear and an increase in the polarization relaxation time, which indicates an increase in the average size of fractal-like structures.

\section{Conclusions}

The generalized Jonesher's law used by us for research of polarization processes quite correctly describes experimental temperature-frequency dependences of complex dielectric permittivity. Based on it, we can analyze the formation and evolution of a fractal-like structure with decreasing temperature of the studied samples, estimate the average grain size, obtain the temperature dependence of its dielectric susceptibility, and draw a conclusion about the dominant conduction mechanism in this temperature range. Although it should be noted that in our case the relaxation time $\tau$ does not correspond to the maximum of the curve describing the frequency dependence of the tangent of the dielectric loss angle in the low frequency range, and has large value. In our opinion, large values of relaxation time are due to the presence of ferroelectric properties of spinels, which are found in them in the temperature range 350 - $400 \mathrm{~K}$ [6].

It is established that the increase of aluminum content in the samples leads to a significant decrease in the temperature at which the manifestation of the multilevel dispersed structure begins. In this case, the frequency corresponding to the maximum of the curve describing the dispersion of the tangent of the dielectric loss angle decreases, i.e. the size of fractal-like formations at a given temperature will be larger. And the increase in the tangent 
of the dielectric loss angle, which at first glance contradicts the obvious fact that the increase in aluminum content in the samples reduces the hopping conductivity due to the replacement of divalent iron ions by trivalent aluminum ions, can be explained by the fact that if the dielectric permittivity $\left(\varepsilon^{\prime}\right)$ decreases faster than the conductivity $\left(\varepsilon^{\prime \prime}\right)$, the tangent of the dielectric loss angle will naturally increase.
Vakalyuk A.V. - Postgraduate student of the Materials Science and Emerging Technologies department;

Vakalyuk V.M. - PhD of Physical and Mathematical Sciences, Associate Professor of Physics department; Hasiuk M.I. - Postgraduate student of the Materials Science and Emerging Technologies department;

Hasiuk I.M. - Doctor of Physical and Mathematical Sciences, Professor of the Department of Materials Science and Emerging Technologies.

[1] O.M. Uhorchuk, V.V. Uhorchuk, M.V. Karpets, L.S. Kaykan, B.Ja. Deputat, A.M.Boychuk, M.I. Hasyuk, Journal of Nano- \& Electronic Physics 7(2), 02012 (2015).

[2] V.O. Kotsyubinsky, V.V. Moklyak, A.B. Grubyak, P.I. Kolkovsky, A.H. Al-Saedi, Journal of Nano-and Electronic Physics 5(1), 01024 (2013).

[3] B.K. Ostafiychuk, I.M. Gasyuk, V.V. Moklyak, B.Y. Deputat, I.P. Yaremiy, Metal Physics and Newest Technologists 32(2), 209 (2010).

[4] B.K. Ostafiychuk, O.V. Kopaev, I.M. Gasyuk, Functional Materials 6(4), 686 (1999).

[5] I.M. Gasyuk, V.V. Ugorchuk, L.S. Kaykan, B.J. Deputat, Journal of Vasyl Stefanyk Precarpathian National University 1(1), 74 (2014).

[6] B. Ostafiychuk, B. Deputat, L. Kaykan, V. Pylypiv and O. Ugorchuk, International Conference on Oxide Materials for Electronic Engineering - fabrication, properties and applications (OMEE-2014, 2014). P. 115; https://doi.org/10.1109/OMEE.2014.6912366.

[7] I.M. Gasyuk, A.V. Vakalyuk, V.M. Vakalyuk, Materials Today: Proceedings 35(4), 567 (2021); https://doi.org/10.1016/j.matpr.2019.10.103.

[8] A.A. Volkov, G.V. Kozlov, S.P. Lebedyev, A.S. Rakitin, Solid State Physics 32(2), 329(1990).

[9] I.I. Popov, R.R. Nigmatullin, A.A. Khamzin, and I.V. Lounev, Journal of Applied Physics 112, 094107 (2012); https://doi.org/10.1063/1.4764343.

[10] B.K. Ostafiychuk, I.M. Gasyuk, L.S. Kaykan, V.V. Uhorchuk, P.P. Yakubovskiy, V.A. Tsap, Yu. S. Kaykan, Metal Physics snd Newest Technologists 36(1), 89 (2014).

[11] M. Abdullah Dar, Khalid Mujasam Batoo, Vivek Verma, W.A. Siddiqui, R.K. Kotnala, J. Alloys and Compounds 493, 553 (2010); https://doi.org/10.1016/j.jallcom.2009.12.154.

\title{
А.В. Вакалюк ${ }^{1}$, В.М. Вакалюк ${ }^{2}$, М.І. Гасюк ${ }^{1}$ I.М. Гасюк ${ }^{1}$ \\ Механізми електричної поляризації розвпорядкованих систем на основі Al-заміщеної LiFe-оксошпінелі
}

\footnotetext{
${ }^{1}$ Прикарпатський начіональний університет імені Василя Стефаника, Івано-Франківськ, Украӥна

${ }_{2}^{2}$ Івано-Франківський національний технічний університет нафти і газу, Івано-Франківськ, Украӥна
}

\begin{abstract}
Методом імпедансної спектроскопії отримані температурно-частотні залежності діелектричної проникності і провідності $\mathrm{Li}_{2} \mathrm{O}-\mathrm{Fe}_{2} \mathrm{O}_{3}-\mathrm{Al}_{2} \mathrm{O}_{3}$ керамік в інтервалі температур 298-648 K. Їх аналіз вказує на присутність фрактальноподібної структури в досліджуваних зразках, вплив якої проявляється за низьких температур. Для дослідження явища електричної поляризації, пов'язаного із цією структурою, використаний узагальнений закон Джоншера. Виявлена істотна залежність дисперсії діелектричних $\mathrm{i}$ провідних властивостей цих шпінельних керамік від температури та вмісту алюмінію в них.

Ключові слова: імпедансна спектроскопія, шпінель, фрактальноподібна структура, частотна дисперсія діелектричної проникності, діелектрична сприйнятливість, тангенс кута діелектричних втрат, стрибковий механізм провідності.
\end{abstract}

